\title{
Stenotrophomonas maltophilia: an unusual pathogen for pneumonia in an immunocompetent patient
}

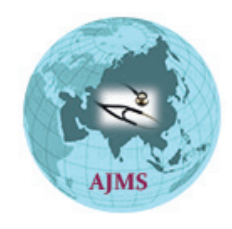

Sir,

Stenotrophomonas maltophila, previously known as Pseudomonas maltophilia, is a saprophyte and an opportunistic pathogen. In comparison to Pseudomonas aeruginosa, its ability to colonize patients or cause infections is limited. ${ }^{1}$

A 45 year old male, with no comorbidities, was referred from a local hospital with the diagnosis of lower respiratory tract infection. He had 7 days history of fever with chills and dry cough. He had received intravenous ceftriaxone and oral doxycycline for 4 days; but there was no relief of symptoms.

On presentation, he was conscious and oriented, with a temperature of $101^{\circ} \mathrm{F}$. His heart rate was $100 /$ minute, blood pressure $110 / 70 \mathrm{mmHg}$, respiratory rate 28 / minute and saturation $90 \%$ in room air. His systemic examinations revealed right sided lung crepitations and associated rhonchi. Chest Xray showed right upper and middle zone consolidation (Figure 1) with was confirmed on CT thorax. His blood investigations showed leucocytosis $(18,200 / \mathrm{cmm})$ with neutrophilia (N94 L4 E2). Renal and liver parameters, electrolytes, PT/INR and aPTT were normal. He was started on intravenous meropenem $(500 \mathrm{mg} \mathrm{q} 8 \mathrm{~h}$ ), oral clarithromycin (500mg twice daily) and oral linezolid (600mg twice daily) along with bronchodilator nebulizations. On day 3 of admission, his condition remained unchanged. His total counts became 22,600/cmm. Throat swab for H1N1 and Mantoux test was negative. Blood cultures were sterile. Bronchoscopy was done and broncho alveolar lavage culture grew Stenotrophomonas maltophila; which was resistant to all antibiotics (including carbapenems) except levofloxacin and trimethoprim-sulfamethoxazole (TMP-SMX). Meropenem, linezolid and clarithromycin were stopped, and the patient was started on intravenous levofloxacin (750mg once daily) and double strength TMP-SMX (twice daily) orally. By day 6 of admission, his respiratory rate became $20 /$ minute and saturation $96 \%$ (room air). Total counts also started normalizing;

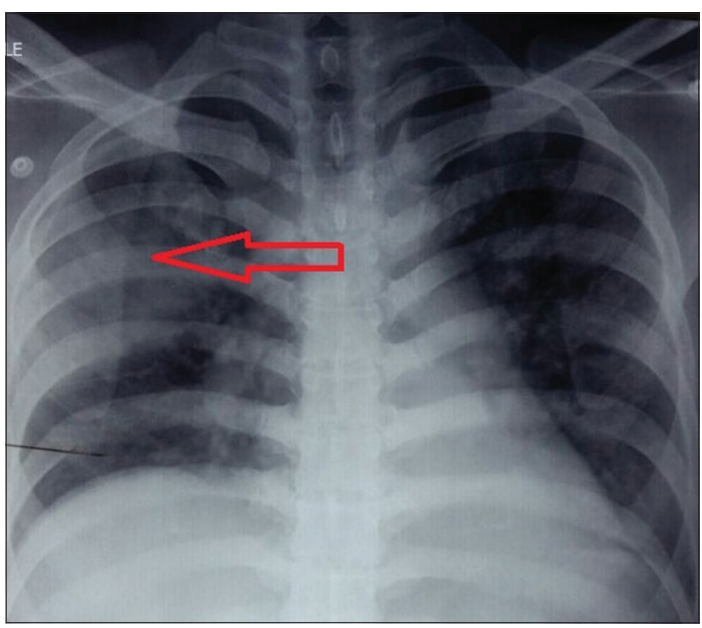

Figure 1: Chest Xray showing right upper and middle zone consolidation

and patient was discharged on day 10 of admission in stable condition.

Stenotrophomonas maltophila infections are commonly seen in immunecompromised patients. These organisms show resistance to broad spectrum antibiotics like carbapenems and advanced cephalosporins. This is due to the possession of antibiotic efflux pumps and L1 and L2 $\beta$-lactamases which cause $\beta$-lactam resistance. These organisms are commonly seen in respiratory tract of ventilated patients, thereby causing ventilator associated pneumonia. Central venous catheter associated infections have been noticed in cancer patients. These organisms are usually susceptible to TMP-SMX, levofloxacin, ticarcillinclavulanate and tigecycline. ${ }^{1}$

Septicemia with Stenotrophomonas maltophila is rather uncommon. The cases reported include endocarditis, 
meningitis, skin lesions, intra-abdominal abscess, elbow infection, pneumonia, otitis externa, dacryocystitis and keratitis. ${ }^{2-10}$ However, in most of these cases, the patients had undergone a procedure or had an immunecompromised state. Our patient was immunecompetent and had no history of interventional procedures or implants. This case, therefore, highlights the emergence of Stenotrophomonas maltophila as a pathogen for pneumonia in immunecompetent patients, and its consideration in patients not responding to broad spectrum antibiotics.

Key words: Stenotrophomonas maltophila, Pneumonia, Carbapenems

\section{Robin George Manappallil' Mele Chelakkoth Sabir ${ }^{2}$}

${ }^{1}$ Consultant, Department of Internal Medicine, Baby Memorial Hospital, Calicut, Kerala 673004, India, ${ }^{2}$ Consultant, Department of Pulmonary Medicine, Baby Memorial Hospital, Calicut, Kerala 673004, India

Address for correspondence: Robin George Manappallil, Consultant, Department of Internal Medicine, Baby Memorial Hospital, Calicut, Kerala 673004, India. Tel: 0091-8547753396.

E-mail: drrobingeorgempl@gmail.com

\section{REFERENCES}

1. Ramphal R. Infections Due to Pseudomonas Species and Related Organisms In: Kasper, Fauci, Hauser, Longo, Jameson,
Loscalzo (ed). Harrison's Principles of Internal Medicine. $19^{\text {th }}$ ed. McGraw Hill education. pp. 1048.

2. Gutiérrez Rodero F, Masiá MM, Cortés J, Ortiz de la Tabla V, Mainar V and Vilar A. Endocarditis caused by Stenotrophomonas maltophilia: case report and review. Clin Infect Dis 1996; 23(6):1261-1265.

3. Yemisen M, Mete B, Tunali Y, Yentur E and Ozturk R. A meningitis case due to Stenotrophomonas maltophilia and review of the literature. Int J Infect Dis 2008; 23: 1-3.

4. Teo WY, Chan MY, Lam CM and Chong CY. Skin manifestation of Stenotrophomonas maltophilia infection--a case report and review article. Ann Acad Med Singapore 2006; 35(12):897-900.

5. Lim DR, Kuk JC, Kim T and Shin EJ. Unusual case of rapid growing intraabdominal abscess caused by Stenotrophomonas maltophilia after laparoscopic appendectomy due to perforated appendicitis: A case report. Medicine (Baltimore). 2017;96(20):e6913.

6. Yamaguchi K, Adams R and Morrey B. Infection after total elbow arthroplasty. J Bone Joint Surg Am 1998; 80:481-491.

7. Gasparetto EL, Bertholdo DB, Davaus T, Marchiori E and Escuissato DL. Stenotrophomonas maltophilia pneumonia after bone marrow transplantation: case report with emphasis on the high-resolution CT findings. Br J Radiol 2007;80(949):e19-e20.

8. Al-Ghamdi KB, Rammal AA and Sindi RS. Otitis externa due to Stenotrophomonas maltophilia in an immune competent patient: Case report. Journal of Infectious Diseases and Immunity 2012;4(2): 20-22.

9. Wladis EJ. Dacryocystitis secondary to Stenotrophomonas maltophilia infection. Ophthal Plast Reconstr Surg 2011: 27(5):e116-e117.

10. Holifield K and Lazzaro DR. Case report: spontaneous Stenotrophomonas maltophilia keratitis in a diabetic patient. Eye Contact Lens 2011;37(5):326-327.

\section{Authors Contribution:}

RGM- Concept and design of case report, reviewed the literature, manuscript preparation and treating physician; MCS- Critical revision of the manuscript and treating pulmonologist.

ORCID ID:

Dr. Robin George Manappallil - (1) http://orcid.org/0000-0003-3973-6800

Source of Support: Nil, Conflict of Interest: None declared. 